\title{
Article
}

\section{Packing and Disorder in Substituted Fullerenes}

Naga Rajesh Tummala, Shaaban Ali Kamel Elroby, Saadullah G.

Aziz, Chad Risko, Veaceslav Coropceanu, and Jean-Luc Bredas

J. Phys. Chem. C, Just Accepted Manuscript • DOI: 10.1021/acs.jpcc.6b05197 • Publication Date (Web): 15 Jul 2016

Downloaded from http://pubs.acs.org on July 19, 2016

\section{Just Accepted}

"Just Accepted" manuscripts have been peer-reviewed and accepted for publication. They are posted online prior to technical editing, formatting for publication and author proofing. The American Chemical Society provides "Just Accepted" as a free service to the research community to expedite the dissemination of scientific material as soon as possible after acceptance. "Just Accepted" manuscripts appear in full in PDF format accompanied by an HTML abstract. "Just Accepted" manuscripts have been fully peer reviewed, but should not be considered the official version of record. They are accessible to all readers and citable by the Digital Object Identifier (DOI®). "Just Accepted" is an optional service offered to authors. Therefore, the "Just Accepted" Web site may not include all articles that will be published in the journal. After a manuscript is technically edited and formatted, it will be removed from the "Just Accepted" Web site and published as an ASAP article. Note that technical editing may introduce minor changes to the manuscript text and/or graphics which could affect content, and all legal disclaimers and ethical guidelines that apply to the journal pertain. ACS cannot be held responsible for errors or consequences arising from the use of information contained in these "Just Accepted" manuscripts. 


\title{
Packing and Disorder in Substituted Fullerenes
}

\author{
Naga Rajesh Tummala, ${ }^{1, *}$ Shaaban A. Elroby, ${ }^{2,3}$ Saadullah G. Aziz, ${ }^{2}$ Chad \\ Risko, ${ }^{4}$ Veaceslav Coropceanu, ${ }^{1}$ and Jean-Luc Brédas ${ }^{5,1, *}$
}

\author{
${ }^{1}$ School of Chemistry and Biochemistry \& Center for Organic Photonics and Electronics, \\ Georgia Institute of Technology, Atlanta, Georgia 30332-0400, USA \\ ${ }^{2}$ Department of Chemistry, King Abdulaziz University, \\ Jeddah 21589, Kingdom of Saudi Arabia \\ ${ }^{3}$ Department of Chemistry, Faculty of Science, Beni-Suef University, \\ Beni-Suef 62511, Egypt \\ ${ }^{4}$ Department of Chemistry \& Center for Applied Energy Research (CAER), \\ University of Kentucky, Lexington, Kentucky 40506-0055, USA \\ ${ }^{5}$ Solar and Photovoltaics Engineering Research Center, \\ Physical Science and Engineering Division, \\ King Abdullah University of Science and Technology, \\ Thuwal 23955-6900, Kingdom of Saudi Arabia
}

\begin{abstract}
Corresponding authors: nagarajesh@gatech.edu (+1-(404)385-8162, jeanluc.bredas@kaust.edu.sa (+966-(0)12-808-4855)
\end{abstract}




\begin{abstract}
Fullerenes are ubiquitous as electron-acceptor and electron-transport materials in organic solar cells. Recent synthetic strategies to improve the solubility and electronic characteristics of these molecules have translated into a tremendous increase in the variety of derivatives employed in these applications. Here, we use molecular dynamics (MD) simulations to examine the impact of going from mono-adducts to bis- and tris-adducts on the structural, cohesive, and packing characteristics of $[6,6]$-phenyl- $\mathrm{C}_{60}$-butyric acid methyl ester $(\mathrm{PCBM})$ and indene- $\mathrm{C}_{60}$. The packing configurations obtained at the MD level then serve as input for density functional theory calculations that examine the solid-state energetic disorder (distribution of site energies) as a function of chemical substitution. The variations in structural and site-energy disorders reflect the fundamental materials differences among the derivatives and impact the performance of these materials in thin-film electronic devices.
\end{abstract}




\section{Introduction}

Materials derived from fullerene derivatives are extensively used as active elements in organic electronic devices, in particular in organic photovoltaics (OPV). ${ }^{1-5}$ The ability to use synthetic methods to tune their solution processability and (opto)electronic properties, ${ }^{6}$ coupled with the propensity of these spherical/ellipsoidal molecules to form three-dimensional aggregate networks with extended percolation pathways in the solid state, have made fullerenes the electron-acceptor material of choice for OPV. ${ }^{7}$ While substituted fullerenes have been the target of a multitude of theoretical investigations (based on quantum-chemical calculations, all-atom molecular dynamics (MD) simulations, and coarse-grained simulations) and experimental studies, $1,8-21$ there remain fundamental characteristics to be better understood in order to improve the design of new fullerene-based materials.

Earlier work explored the impact of the number of solubilizing adducts appended on the fullerene framework, i.e., mono-, bis-, and tris-substitutions, on the packing structure and electronic characteristics (including site-energy disorder) in thin films of $[6,6]-$ phenyl- $\mathrm{C}_{60^{-}}$ butyric acid methyl ester (PCBM). Major aspects of interest included the variation in coordination numbers of PCBM multi-adducts as well as the description of the percolation pathways based on the varying thresholds of magnitudes of electronic coupling among neighboring molecules. ${ }^{9}$ An important conclusion was that the coordination numbers, as well as the percolation lengths, decreased as a function of the number of fullerene adducts. Kinetic Monte Carlo studies pointed to reduced electron mobilities in multi-adduct PCBMs when compared to mono-adduct PCBM, due to increased reorganization energy, isomeric disorder, ${ }^{8}$ and structural disorder. ${ }^{11}$ In these studies, however, the magnitudes of the electronic disorders due to inductive effects from neighboring molecules and intra- and intermolecular vibrations, 
were not quantified and simply considered on an empirical basis. The exact nature and extent of disorder are, however, key elements for an in-depth understanding of the charge-transport properties. $^{22}$ Hence, an accurate evaluation, in particular, of how disorder evolves as a function of the number of adducts would be a significant step towards this understanding. This is the major objective of the present work.

We report here on a comprehensive theoretical investigation focusing on the evolution of energetic disorder (due to variations in site energies) as a function of the number of fullerene adducts. We discuss the influence of the number, nature, and substitution pattern of the adducts on the $\mathrm{C}_{60}$ fullerene cage for the compounds shown in Figure 1.

\section{Computational Details}

Molecular dynamics (MD) simulations of the mono-, bis-, and tris- adducts of PCBM (chemical formulas $-\left(\mathrm{C}_{72} \mathrm{H}_{14} \mathrm{O}_{2}\right),-\left(\mathrm{C}_{84} \mathrm{H}_{28} \mathrm{O}_{4}\right)$, and $-\left(\mathrm{C}_{96} \mathrm{H}_{42} \mathrm{O}_{6}\right)$, respectively) and indene- $\mathrm{C}_{60}$ (chemical formulas $-\left(\mathrm{C}_{69} \mathrm{H}_{8}\right),-\left(\mathrm{C}_{78} \mathrm{H}_{16}\right)$, and $-\left(\mathrm{C}_{87} \mathrm{H}_{24}\right)$, respectively), see Figure 1, were carried out using the GROMACS 4.6.2 software suite. Bis-isomers were chosen such that the distance between the adduct moieties on the fullerene cages is small (at position ee for bis2, making this bis-adduct less symmetric) in one of the isomers and the largest in another (at position trans-1 for bis1, making this bis-adduct more symmetric). A recent study indicates that the anisotropy of the polarizabilities are the lowest and highest for bis2- and bis 1 - isomers, respectively. ${ }^{23}$ The adduct positions on the tris-adducts are selected from a combination of adduct positions in the two bisisomers. The OPLS-AA ${ }^{24}$ (Optimized Potentials for Liquid Simulations-All Atom) force-field parameters were used to simulate the fullerenes, as we and others have shown that this force field 
accurately predicts many of the bulk properties of $\mathrm{C}_{60}, \mathrm{PCBM}$, and indene- $\mathrm{C}_{60} 11,18,20,21,25-27$ Simulations of amorphous PCBM and mono-indene- $\mathrm{C}_{60}$ have been described in our previous publications. ${ }^{26-28}$ The phenyl-butyric acid methyl ester adduct $\left(\mathrm{C}_{12} \mathrm{H}_{14} \mathrm{O}_{2}\right)$ induces a dipole moment in PCBM, whose magnitude (between 1.5 and $5 \mathrm{D}$ ) varies with the orientation of the ester group with respect to the phenyl group; the indene adduct $\left(\mathrm{C}_{9} \mathrm{H}_{8}\right)$ brings a dipole moment of ca. 3 D. We have recently shown that these variations in adduct polarity affect the cohesive characteristics of pure fullerene and P3HT:fullerene blend thin films. ${ }^{27}$
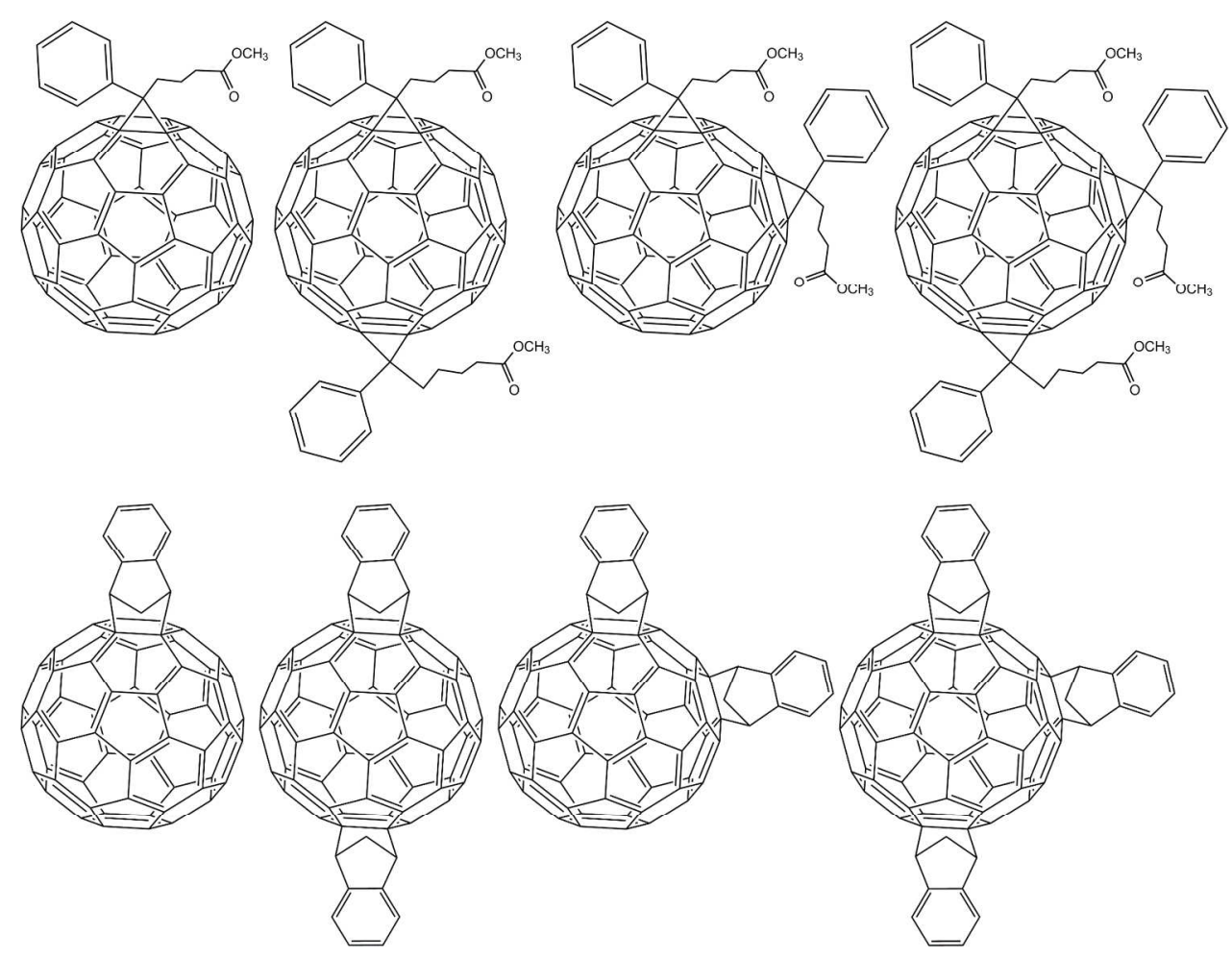

Figure 1: (From left to right) Mono-, bis1-, bis2-, and tris- adducts of PCBM (top panel) and indene- $\mathrm{C}_{60}$ (bottom panel). The mono-, bis- and tris- adducts of indene- $\mathrm{C}_{60}$ are generally referred to as ICMA, ICBA, and ICTA, respectively. Note that there are many isomers possible depending on the positions of the adducts on the $[6,6]$ or $[6,5]$ or $[5,5]$ ring of the fullerene molecule. 
For the sake of completeness, we briefly recall our simulation procedure. It consists of randomly placing 512 (in some cases 400) fullerene molecules in a simulation box at a density $<0.3 \mathrm{gm} / \mathrm{cc}$, followed by NPT equilibration (constant number of molecules, pressure, and temperature) at $1000 \mathrm{~K}$ and $1 \mathrm{~atm}$. The equilibrated simulation box is further simulated for 2 to $10 \mathrm{~ns}$ before, gradually, cooling the system down to $100 \mathrm{~K}$ in discrete steps of $50 \mathrm{~K}$ every $500 \mathrm{ps}$. The final 250 ps of these discrete interval simulations are then used to compute the thermodynamic and physical properties. The density $v s$. temperature plots are used to identify first-order phase transitions, as described elsewhere. ${ }^{28,29}$ Rigorously speaking, first-order phase transitions involve discontinuity in the order parameter; however, since here we only consider changes in the slope of density as a function of temperature, we refer to these as pseudo first-order phase transitions. To analyze the structural order within the fullerene simulations, we compute the Steinhardt (or bond-order) parameters, ${ }^{30,31}$ which are based on the orientations and numbers of neighboring molecules. A bonding criterion of $1.1 \mathrm{~nm}$ (i.e., only molecules that are less than $1.1 \mathrm{~nm}$ away when taking the center of mass-to-center of mass distances between neighbors) is considered for the analysis.

Following previous work, ${ }^{27}$ we use the charge equilibration method to compute the extent of energetic disorder among the highest-occupied molecular orbital (HOMO) eigenvalues of the fullerene radical-anions, which represent the site energies of the fullerene anions. The overall energetic disorder consists of two contributions, referred as dynamic disorder $\left(\sigma_{\mathrm{D}}\right)$ and static disorder $\left(\sigma_{\mathrm{S}}\right)$. The dynamic disorder is related to electron-vibration interactions that result in time-dependent variations of the site energies. The static energetic disorder arises from the modulations in site energies due to the permanent loss of site equivalency as the system approaches / corresponds to an amorphous phase. In order to evaluate the total disorder, we 
relied on 200 clusters within the ensemble of 512 molecules, each containing a central molecule and the nearest-neighbor molecules within a radius of $1.2 \mathrm{~nm}$ (center-of-mass distances from the central molecule). The atomic positions of the neighboring molecules are represented as point charges, with point charges iteratively optimized at the long-range corrected density functional theory (DFT) $\omega \mathrm{B} 97 \mathrm{XD} / 6-31 \mathrm{G}(\mathrm{d}, \mathrm{p})$ level. The range-separation parameter $\omega$ was optimized (tuned) using a non-empirical procedure. ${ }^{32}$ This approach was shown earlier to describe accurately the energy levels of extended $\pi$-conjugated molecules. ${ }^{32,33}$ The tuned $\omega$ values are 0.150, 0.115, 0.118, and 0.110 $\mathrm{Bohr}^{-1}$ and 0.147, 0.130, 0.134, and 0.122 Bohr $^{-1}$ for mono-, bis1, bis2, and tris-adducts of indene- $\mathrm{C}_{60}$ and PCBM, respectively. The reorganization energies upon charging of the isolated multi-adduct fullerenes are also computed using the non-empirically tuned $\omega \mathrm{B} 97 \mathrm{XD}$ functional; we refer the reader to our recent publication for a full description of this methodology. ${ }^{27}$

To study the dynamic disorder $\left(\sigma_{D}\right)$ of the HOMO eigenvalues of the fullerene anions as a function of time, 20 independent clusters were identified (200 frames separated by at least $50 \mathrm{fs}$ ). We also simulated single (isolated) fullerene-derivative molecules in boxes whose sizes were obtained from the 512-molecule simulations and used the trajectory coordinates (200 frames separated by at least $50 \mathrm{fs}$ ) to compute the relaxation energies for the derivatives considered in this study. The associated relaxation energy values of the anion (denoted as $\lambda_{\mathrm{A}, \mathrm{MD}}$ ) are computed as $\lambda_{\mathrm{A}, \mathrm{MD}}=\left(\sigma_{\mathrm{D}}\right)^{2} /\left(2 \mathrm{k}_{\mathrm{B}} \mathrm{T}\right) .{ }^{34}$ The $\sigma_{\mathrm{D}}$ values are calculated as the standard deviation of the 200 -site energies and are accurate within $0.01 \mathrm{eV}$. The degree of static disorder was obtained by subtracting the dynamic disorder from the total disorder (see below).

Finally, we note that, here, we have not attempted to fully quantify the electron mobilities; this could be done subsequently via kinetic Monte Carlo simulations based on the atomic coordinates 
obtained from the MD trajectories and on the electronic couplings (transfer integrals) between nearest-neighbor molecules, in combination with the static and dynamic disorder parameters. However, we discuss explicitly the major components that directly modulate these electron mobilities among our series of fullerene derivatives, i.e., the numbers of (connected) nearestneighbor molecules and the extent of disorder.

\section{Results \& Discussion}

\section{Packing, Nearest Neighbors, Percolation, and Cohesive Energy}

As underlined in the Introduction, understanding the packing of fullerene derivatives in the amorphous bulk is essential for evaluating the charge-carrier transport properties of these technologically relevant materials. Electron transport is determined by the topological routes in the corresponding networks, which depend on the number of nearest-neighbor contacts among adjacent molecules. Therefore, for each substituted fullerene, it is of interest to evaluate the radial distribution functions and coordination numbers, based on the center-of-mass distances between $\mathrm{C}_{60}$ moieties. The main results are collected in Figures 2, 3, and 4. As reported by Nelson and co-workers, the mono-adducts have the largest number of nearest neighbors followed by the bis- and then the tris- adducts. ${ }^{11}$

At this stage, it is important to note that there are two substitution patterns examined in this study for the bis-substituted fullerenes (bis1 and bis2, see Figure 1), as these are generally found as mixtures with significant isomeric heterogeneity. Also, we recall that, within MD simulations, a useful measure of packing density can be found in the radial distribution functions (RDFs). The RDFs correspond to the ratio between the local packing of molecules and the average packing 
within bulk and hence point to differences in the local packing environments of the molecules under study.

In the case of the PCBM species, the fullerene cages of bis1-PCBM lead to a slightly closer packing (see inset in top-right panel of Figure 2) compared to bis2-PCBM, as identified by the very similar first peaks of the RDFs. This result can be rationalized by the fact that the presence of two adducts close to each other in bis2-PCBM shields more effectively the molecules from each other and increases to some extent the average separation distance between the $\mathrm{C}_{60}$ cages when compared to bis1-PCBM. The RDF differences are not significant beyond the initial valley at 1.1-1.2 nm. As expected, tris-PCBM has the smallest RDF first peak due to increased separation between the fullerene cages. 

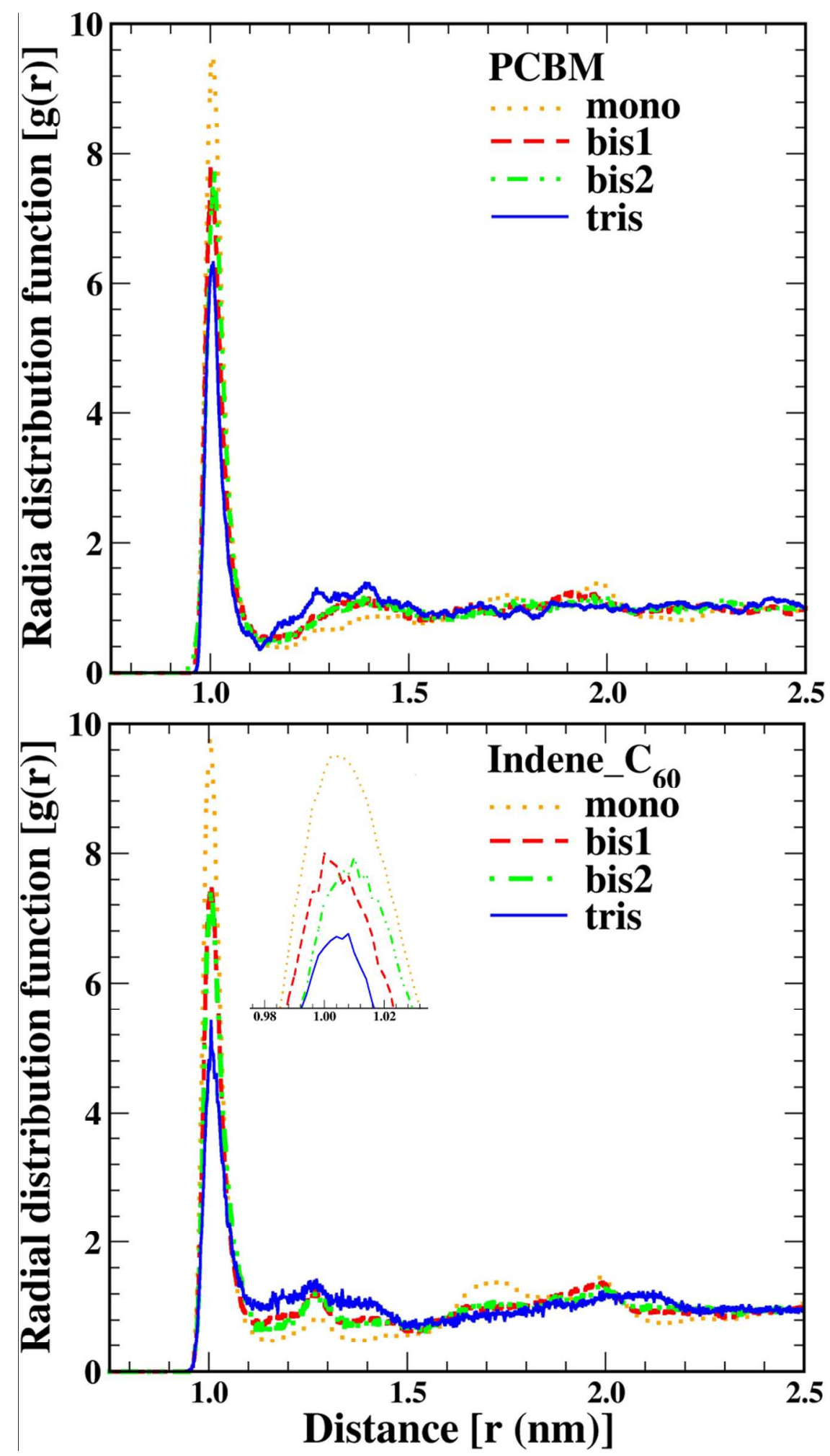

Figure 2: Radial distribution functions (RDFs) between the $\mathrm{C}_{60}$ centers-of-mass for the monoand multi-adduct PCBM (top) and indene- $\mathrm{C}_{60}$ (bottom) systems. 
The coordination numbers (see Figure 3 ) of the $\mathrm{C}_{60}$ cages indicate that the number of nearest neighbor molecules decreases with the number of adducts: The mono-adduct has 8.0 neighbors; the bis-adducts, 5.0 neighbors; and the tris-adduct, 3.7 neighbors. Note that the neighbors within the first shell, especially within a distance of $1.2 \mathrm{~nm}$, are of highest interest with regard to the electronic characteristics; the number of nearest neighbors indeed directly affects the transport pathways available and, as a result, impact the charge-carrier transport properties.

The normalized cluster sizes are shown in Figure 4. When the cluster sizes are analyzed through connection criteria based on center-of-mass distances of less than $1.1 \mathrm{~nm}$, all the monoadduct PCBM molecules are found to be connected to other molecules in the simulation box for the entirety of the simulation time; this results in a normalized cluster size and probability of 1. However, in the cases of bis1-PCBM and bis2-PCBM, a few molecules in the simulation box disconnect from the cluster due to thermal fluctuations (more frequently so for the bis2-adduct than the bis1-adduct of PCBM); this results in a probability of less than one to find the normalized cluster size of 1 . Interestingly, in the case of the PCBM tris-adduct, there exist a few molecules (one to five molecules out of the 512 molecules in the simulation box) that remain not connected to other molecules; hence, the normalized cluster size of 1 is not observed in that instance. This observation underlines that, within the corresponding thin films, a number of trap states can be expected due to the presence of isolated/disconnected molecules. ${ }^{14,35}$

The indene- $\mathrm{C}_{60}$ multi-adducts qualitatively follow packing trends similar to those for the PCBM species. However, here, the packing differences between the bis-adduct isomers are negligible in terms of RDFs and coordination numbers. Also, the presence of a few molecules that remain disconnected from other molecules in the simulation box is observed only in the case of the indene- $\mathrm{C}_{60}$ tris-adduct. 

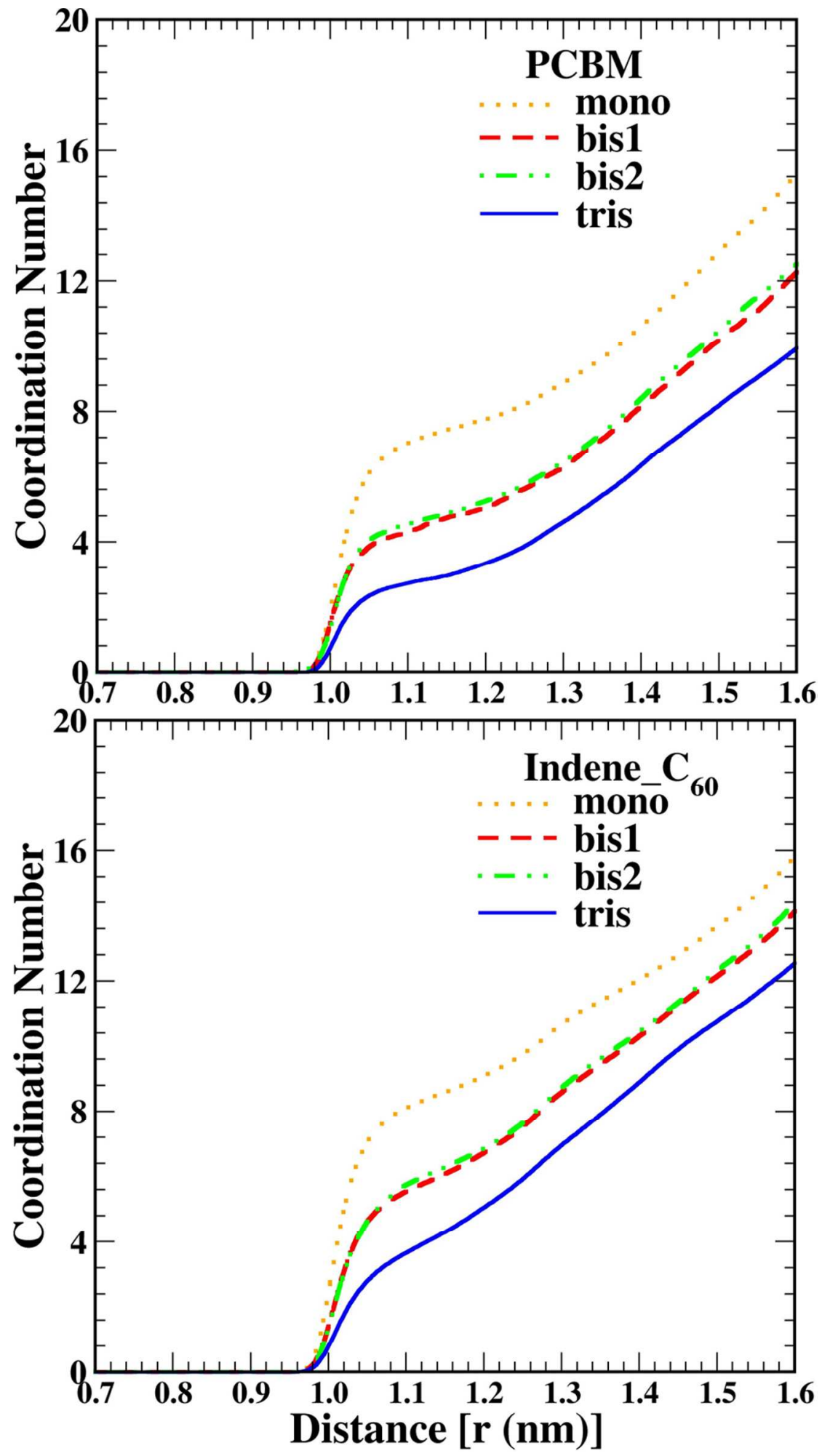

Figure 3: Coordination numbers as a function of distance between the $\mathrm{C}_{60}$ cages for the monoand multi-adduct PCBM (top) and indene- $\mathrm{C}_{60}$ (bottom) systems. 


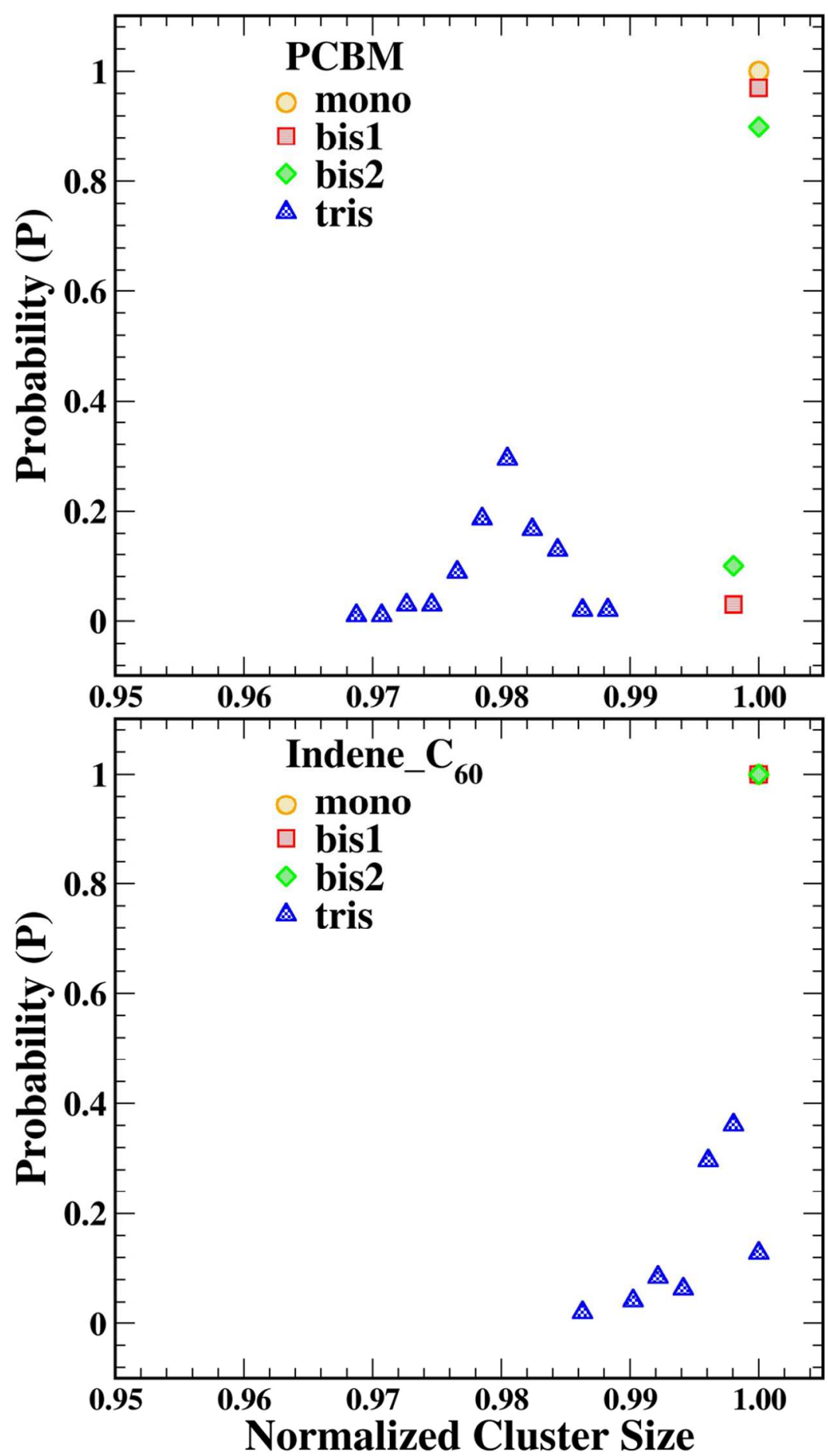

Figure 4: Normalized cluster size distributions for the mono- and multi-adduct PCBM (top) and indene- $\mathrm{C}_{60}$ (bottom) systems. A normalized cluster size of one indicates all the molecules in the simulation box are connected. Only nearest neighbor molecules that are less than $1.1 \mathrm{~nm}$ away from each other (based on center-of-mass distances) are considered for the calculation of the cluster sizes. 
We have previously shown that a slightly higher coordination number for the indene- $\mathrm{C}_{60}$ monoadduct results in a higher tensile modulus when compared to the PCBM analog. ${ }^{27}$ Similarly, the indene- $\mathrm{C}_{60}$ bis-adducts have a larger number of nearest neighbors $(\sim 6.0)$ when compared to the PCBM bis-adducts $(\sim 5.0)$. This result is indicative of the fact that the indene moieties (at least when used as bis-adducts) do not significantly impede close contacts between adjacent fullerene cages; hence, these molecules pack more tightly when compared to fullerenes containing the phenyl-butyric-acid-methyl-ester adducts. Even though the indene- $\mathrm{C}_{60}$ tris-adduct has a higher coordination number than the PCBM tris-adduct (due to a relatively more compact nature), a larger number of isolated molecules is found in the amorphous indene- $\mathrm{C}_{60}$ tris-adduct simulations when compared to the PCBM tris-adduct. Thus, in the case of the tris-adducts, the indene moieties can sometimes shield more effectively the $\mathrm{C}_{60}$ cages from their neighbors, while it is difficult to completely shield the $\mathrm{C}_{60}$ cages with the longer and flexible butyric-acid-methylester adducts. Nevertheless, the fact that isolated molecules are present in both tris-adduct packings confirms the experimental proposition that such isolated molecules can impede electron transport. $^{36,37}$

In order to examine material miscibility, which is a key parameter in the formation of BHJ active layers in OPV, we now turn to an evaluation of the Hildebrand ${ }^{38}$ and Hansen ${ }^{39}$ solubility parameters, see Table 1. The Hildebrand parameter is characterized by $\delta_{T}$ (in units of $\left.\left(\mathrm{cal} / \mathrm{cm}^{3}\right)^{1 / 2}\right)$ and is defined as the square root of the cohesive energy density (the total interaction energy among molecules within a specific volume). The Hildebrand parameter is related to the Hansen parameters $\left(\delta_{D}, \delta_{P}\right.$, and $\delta_{H}$, corresponding to the dispersion, electrostatic, and hydrogenbonding interaction energies, respectively) through the relationship $\delta_{T}^{2}=\delta_{D}^{2}+\delta_{P}^{2}+\delta_{H}^{2} \cdot{ }^{39,40} \mathrm{We}$ observe a consistent decrease in the $\delta_{T}$ value (about $0.5\left(\mathrm{cal} / \mathrm{cm}^{3}\right)^{1 / 2}$ ) with increasing substitution 
of the fullerene cage: From $10.7\left(\mathrm{cal} / \mathrm{cm}^{3}\right)^{1 / 2}[\mathrm{mono}]$ to $10.2\left(\mathrm{cal} / \mathrm{cm}^{3}\right)^{1 / 2}$ [bis] and 10.0 $\left(\mathrm{cal} / \mathrm{cm}^{3}\right)^{1 / 2}$ [tris] for the PCBM compounds, and from $10.0\left(\mathrm{cal}^{1 / \mathrm{cm}^{3}}\right)^{1 / 2}[\mathrm{mono}]$ to $9.5\left(\mathrm{cal} / \mathrm{cm}^{3}\right)^{1 / 2}$ [bis] and $9.0\left(\mathrm{cal} / \mathrm{cm}^{3}\right)^{1 / 2}$ for the indene- $\mathrm{C}_{60}$ compounds; the bis-adduct isomers result in the same $\delta_{T}$ for each fullerene species. As the number of adducts increases, the contributions from dispersion interactions decrease; however, the contributions from electrostatic interactions, which include polar and hydrogen-bonding interactions, $\left(\delta_{P}+\delta_{H}\right)$, increase. The bis 2 adduct of indene- $\mathrm{C}_{60}$ is, however, an exception, the reasons for which are discussed next. For the sake of completeness, we also report the experimentally evaluated parameters for $\mathrm{C}_{60}$ that has a $\delta_{T}$ of 9.8 $\left(\mathrm{cal} / \mathrm{cm}^{3}\right)^{1 / 2}$ with dispersion and electrostatic contributions of 9.6 and $1.9\left(\mathrm{cal} / \mathrm{cm}^{3}\right)^{1 / 2}$, respectively. ${ }^{41}$ From simulations, we obtain a comparable $\delta_{T}$ value of $9.4\left(\mathrm{cal} / \mathrm{cm}^{3}\right)^{1 / 2}$ but with all contributions coming from dispersion interactions.

Table 1: Hildebrand and Hansen parameters for the multi-adduct fullerene derivatives. The term referred to as $\delta_{\mathrm{P}}+\delta_{\mathrm{H}}$ is evaluated as $\left(\delta_{P}^{2}+\delta_{H}^{2}\right)^{1 / 2}$.

\begin{tabular}{l|c|c|c|c|c|c}
\multicolumn{6}{c}{ Hildebrand/Hansen parameters (cal/cm ) } \\
\hline & \multicolumn{3}{|c|}{ PCBM } & \multicolumn{3}{c}{ Indene_C } \\
\hline & $\boldsymbol{\delta}_{\mathbf{T}}$ & $\boldsymbol{\delta}_{\mathbf{D}}$ & $\boldsymbol{\delta}_{\mathbf{P}}+\boldsymbol{\delta}_{\mathbf{H}}$ & $\boldsymbol{\delta}_{\mathbf{T}}$ & $\boldsymbol{\delta}_{\mathbf{D}}$ & $\boldsymbol{\delta}_{\mathbf{P}}+\boldsymbol{\delta}_{\mathbf{H}}$ \\
\hline mono $^{\mathbf{2 7}}$ & 10.7 & 9.9 & 4.0 & 10.0 & 9.8 & 2.0 \\
bis1 & 10.2 & 9.2 & 4.4 & 9.5 & 9.2 & 2.3 \\
bis2 & 10.2 & 9.1 & 4.6 & 9.5 & 9.3 & 1.8 \\
tris & 10.0 & 8.6 & 5.1 & 9.0 & 8.6 & 2.6 \\
\hline
\end{tabular}


The $\left(\delta_{P}+\delta_{H}\right)$ electrostatic contributions for all fullerene derivatives studied here arise from the interactions among the adducts, as the carbon atoms on the fullerene cages do not carry point charges within the OPLS-AA force field. The variations in these contributions can be illustrative of packing changes within the multi-adducts. In particular, an increase in the $\delta_{P}+\delta_{H}$ values suggests closer packing of adduct moieties. The increase in $\delta_{D}$ can be mainly attributed either to increased $\mathrm{C}_{60}-\mathrm{C}_{60}$ interactions or $\mathrm{C}_{60}$-adduct interactions. For PCBM, increasing the number of adducts contributes to increased electrostatic interactions, with these interactions stronger in bis2 when compared to bis1. The trend is not clear for indene- $\mathrm{C}_{60}$, as the decrease in the electrostatic interactions and increase in dispersion interactions for the bis2 adduct indicate rather close packing of the fullerene cages and adducts when compared to bis1. This observation is also confirmed by the RDFs among the fullerene cages and the adducts, which show a larger first peak for the bis 2 adduct than for the bis1 adduct. For the tris-adducts, we observe increased adduct-adduct interactions for both indene- $\mathrm{C}_{60}$ and PCBM.

Experimentally, the higher power conversion efficiency (PCE) obtained in the case of indene- $\mathrm{C}_{60}$ bisadduct-based BHJ solar cells, especially when poly-3-hexyl-thiophene (P3HT) is used as electron-donor component, ${ }^{36,42}$ is considered to result from a better miscibility between P3HT and these fullerene derivatives. The corresponding experimental values of $\delta_{T}, \delta_{D}$, and $\delta_{P}+\delta_{H}$ for P3HT are $9.76\left(\mathrm{cal} / \mathrm{cm}^{3}\right)^{1 / 2}, 9.02\left(\mathrm{cal}^{1 / \mathrm{cm}^{3}}\right)^{1 / 2}$, and $3.67\left(\mathrm{cal} / \mathrm{cm}^{3}\right)^{1 / 2}$, respectively. ${ }^{43}$ The comparison of these parameters with those from Table 1 indeed points to the best match, and thus a better miscibility, for P3HT with bisadducts of indene- $\mathrm{C}_{60}$ (although caution has to be exercised when comparing the solubility parameter values of pure phases to the BHJ morphology). Apart from solubility parameters, processing conditions, such as choice of solvent, annealing temperature, nature of the donor and acceptor molecules, and mixing weight ratio in 
the blend, etc., can potentially change the overall device efficiency. ${ }^{42} \mathrm{We}$ also note that for the systems studied here, the change in adduct moiety changes the electron affinity of the fullerene derivatives and hence the open-circuit voltage of such P3HT-ICBA devices compared to P3HTPCBM devices. ${ }^{42,44}$ With respect to design rules, bis- and tris-adducts that do not hinder significant $\mathrm{C}_{60}-\mathrm{C}_{60}$ interactions are optimal systems since they can be expected to provide both denser packing with large numbers of neighbors as in the case of mono-adducts and increased solubility in processing solvents. In this context, recent reports indicate that substitution of indene in bis-adducts or tris-adducts by dihydromethano groups provides enhanced solubility and also increased efficiency, in spite of the short and rigid nature of these groups. ${ }^{45-47}$

\section{Analysis of the Pseudo First-Order Phase Transitions}

We now turn to the pseudo first-order transitions, which are based on the evaluation of density vs. temperature plots. The results are collected in Table 2. The temperatures at which these transitions occur are indicative of the annealing temperatures required to enhance the thin-film morphological characteristics coming from molecular rearrangements. However, the exact annealing temperatures depend on whether the materials undergo a glass transition or rearrange at temperatures close to the melting point (in the case of systems that do not undergo a glass transition, these first-order phase transition temperatures indicate the maximum annealing temperatures). For example, PCBM undergoes a glass transition at $c a .131^{\circ} \mathrm{C}$, which is much lower and difficult to predict from molecular simulations than the melting point at $\sim 270{ }^{\circ} \mathrm{C}$, and finally decomposes at $c a .390^{\circ} \mathrm{C} .{ }^{48,49}$ 
The melting temperatures are found to decrease with an increasing number of adducts. This trend can be expected since the overall interaction energy (cohesive energy) deduced from the Hildebrand parameters decreases. The decreasing number of $\mathrm{C}_{60}$ neighbors, because of the increased number of adducts or due to adduct positions, allows for a larger magnitude of the translational motion of the fullerene cage with increasing temperature, which acts to lower the transition temperature. ${ }^{50,51} \mathrm{We}$ note that the calculated melting temperatures are consistently higher than the experimental values by at least $100 \mathrm{~K}$; the reason is that, within the simulations, super-heating effects are observed when determining the transition points, which tends to increase the simulated transition temperatures. ${ }^{26}$ While alternate methodologies are available for determining these transition temperatures more accurately, ${ }^{29}$ for the purpose of comparison among the fullerene derivatives, the results we obtain here provide reliable trends.

Table 2: Pseudo first-order phase transitions calculated from a series of simulations at varying temperatures for the fullerene derivatives considered in this study. The error bars for the density are less than $0.003 \mathrm{~g} / \mathrm{cc}$.

\begin{tabular}{|l|c|c|}
\multicolumn{1}{|c|}{ Fullerene System } & $\begin{array}{c}\text { Density@ } \\
\mathbf{3 0 0} \mathbf{K} \\
\text { (g/cc) }\end{array}$ & $\begin{array}{c}\text { Pseudo First } \\
\text { Order Phase } \\
\text { Transition (K) }\end{array}$ \\
\hline mono & 1.507 & $690-700$ \\
bis1 & 1.418 & $595-605$ \\
bis2 & 1.417 & $595-605$ \\
tris & 1.325 & $565-575$ \\
mono Indene_C60 & 1.563 & $640-650$ \\
bis1 & 1.471 & $610-630$ \\
bis2 & 1.485 & $540-560$ \\
tris & 1.397 & $470-490$
\end{tabular}


The mono and multi-adducts of indene- $\mathrm{C}_{60}$ are consistently calculated to have lower melting temperatures and higher densities than the PCBM derivatives, which is consistent with their lower Hildebrand parameters. Interestingly, the bis 1 adduct of indene- $\mathrm{C}_{60}$ has a somewhat higher transition temperature, even though the overall interaction energy deduced from the Hildebrand parameters is stronger in bis 1 PCBM. This discrepancy is due to the slightly more ordered packing in bis 1 indene- $\mathrm{C}_{60}$ compared to other bis-adducts of indene- $\mathrm{C}_{60}$ and $\mathrm{PCBM},{ }^{30,52}$ as evaluated from the bond order parameter calculations (we recall that the distribution of the number of nearest molecules we discussed earlier (see Figure 2) showed insignificant differences). We note that, even in calorimetry experiments on indene- $\mathrm{C}_{60}$ bis-adducts, no endothermic peaks indicative of melting are observed while the gravimetric analysis indicates that the indene- $\mathrm{C}_{60}$ bis-adduct decomposes around $270^{\circ} \mathrm{C}$. These results confirm that the firstorder transition in these adducts are not easily observable and that these materials are inherently glassy, rather than crystalline, as in the case of mono-adducts. ${ }^{53-55}$ A recent study indicates that the electron mobility in thin-film devices of ICBA can be up to $0.1 \mathrm{~cm}^{2} \mathrm{~V}^{-1} \mathrm{~s}^{-1}$, when ICBAsubstrate interactions are tuned and the films are annealed at as high as $200{ }^{\circ} \mathrm{C} .{ }^{55}$ Finally, as seen in the Hildebrand parameters, the lowest transition temperature is observed for the tris-adduct of indene- $\mathrm{C}_{60}$ and the difference between the transition temperatures is highest between the trisadducts of indene- $\mathrm{C}_{60}$ and PCBM.

\section{Energetic Disorder}

We now focus on understanding the extent of energetic disorder in the thin films of the fullerene derivatives. We first evaluate the reorganization energies, i.e., the change in energy associated 
with geometry relaxations upon redox processes. In general, smaller reorganization energies go hand in hand with better charge-carrier transport properties. ${ }^{22}$

We recall that in the context of electron-transfer theory the intramolecular reorganization energy consists of the sum of two geometry relaxation energies: the first one related to adding an electron to the neutral molecule, denoted here as $\lambda_{\mathrm{A}}$; and the second one related to removing an electron from the molecular anion, denoted here as $\lambda_{\mathrm{N}}$. Our calculations of $\lambda_{\mathrm{A}}$ for the mono, bis, and tris-adducts of indene- $\mathrm{C}_{60}$ yield values (see Table 3) in the range of 0.082-0.094 eV; the neutral relaxation energies $\left(\lambda_{N}\right)$ are within the same range. The largest reorganization energy $(0.189 \mathrm{eV})$ is found for the symmetric bis-adduct of indene- $\mathrm{C}_{60}$, while the other indene-adducts have slightly smaller reorganization energies $(c a .0 .17 \mathrm{eV})$.

Table 3: DFT estimates of the relaxation energies of anion and neutral molecules $\left(\lambda_{\mathrm{A}}\right.$ and $\left.\lambda_{\mathrm{N}}\right)$ and reorganization energies $(\lambda)$ computed from the adiabatic potential energy surfaces using the optimally-tuned $\omega \mathrm{B} 97 \mathrm{XD}$ functional. The $\boldsymbol{\lambda}_{\mathrm{A}, \mathbf{M D}}\left(\sigma_{\mathrm{D}}\right)$ relaxation energies are computed from the standard deviation of the distribution of HOMO eigenvalues for the anionic fullerene derivatives.

\begin{tabular}{|c|c|c|c|c|c|c|c|c|}
\hline \multicolumn{9}{|c|}{$\begin{array}{c}\text { Single Molecule Anion }\left(\lambda_{A}\right) \text { and Neutral }\left(\lambda_{N}\right) \text { Relaxation Energies and } \\
\text { Overall }(\lambda) \text { Reorganization Energies }(\mathrm{eV})\end{array}$} \\
\hline & \multicolumn{4}{|c|}{ Indene- $C_{60}$} & \multicolumn{4}{|c|}{ PCBM } \\
\hline & $\lambda_{\mathrm{A}}$ & $\begin{array}{c}\lambda_{\mathrm{A}, \mathrm{MD}} \\
\left(\boldsymbol{\sigma}_{\mathrm{D}}\right)\end{array}$ & $\lambda_{\mathrm{N}}$ & $\lambda$ & $\lambda_{\mathrm{A}}$ & $\begin{array}{c}\lambda_{\mathrm{A}, \mathrm{MD}} \\
\left(\sigma_{\mathrm{D}}\right)\end{array}$ & $\lambda_{N}$ & $\lambda$ \\
\hline mono & 0.083 & $\begin{array}{c}0.09 \\
(0.068)\end{array}$ & 0.082 & 0.165 & 0.089 & $\begin{array}{c}0.11 \\
(0.077)\end{array}$ & 0.088 & 0.177 \\
\hline bis1 & 0.094 & $\begin{array}{c}0.09 \\
(0.069)\end{array}$ & 0.095 & 0.189 & 0.096 & $\begin{array}{c}0.12 \\
(0.078)\end{array}$ & 0.091 & 0.187 \\
\hline bis2 & 0.086 & $\begin{array}{c}0.09 \\
(0.067)\end{array}$ & 0.084 & 0.170 & 0.218 & $\begin{array}{c}0.23 \\
(0.108)\end{array}$ & 0.092 & 0.310 \\
\hline tris & 0.082 & $\begin{array}{c}0.11 \\
(0.074)\end{array}$ & 0.086 & 0.168 & 0.149 & $\begin{array}{c}0.16 \\
(0.090)\end{array}$ & 0.071 & 0.220 \\
\hline
\end{tabular}


The reorganization energies of the multi-adduct PCBMs are significantly larger than that of the mono-adduct PCBM, except for the bis1-adduct of PCBM. The relaxation energies $\lambda_{\mathrm{A}}$ and $\lambda_{\mathrm{N}}$ in the mono adduct and bis1-adduct are only slightly asymmetric; for example, $\lambda_{\mathrm{A}}$ for bis1 PCBM is $0.096 \mathrm{eV}$ and $\lambda_{\mathrm{N}}$ is $0.091 \mathrm{eV}$, resulting in a reorganization energy of $0.187 \mathrm{eV}$. As the bis 2 adduct of PCBM has less symmetry than the bis 1 adduct, the HOMO electron density in the bis2 anion is more localized, which leads to a further increase in the difference between $\lambda_{\mathrm{A}}=0.218$ $\mathrm{eV}$ and $\lambda_{\mathrm{N}}=0.092 \mathrm{eV}$, and a total reorganization energy of $0.310 \mathrm{eV}$. We also observe a larger reorganization energy for the tris-adduct of PCBM compared to the mono-adduct (with a value approximately half the sum of the bis 1 and bis 2 values). Thus, while the relatively rigid indene adduct does not significantly alter the radical-anion and neutral molecular geometries and consequently the relaxation energies, multiple substitutions with phenyl-butyric-acid methyl ester increase the relaxation energies and would be detrimental for charge transport. ${ }^{22,}{ }^{56}$ The results are also indicative that the adduct positions affect electron localization and, hence, the reorganization/relaxation energy when using phenyl-butyric-acid methyl ester substituents. We would like to mention that the excess electron in the DFT optimized structures of anionic fullerene multi-adducts is delocalized over the fullerene cage; however, the interaction between the adduct moiety and the fullerene cage can influence the extent of delocalization.

As mentioned earlier, the dynamic disorder depends on electron-vibration interactions. The standard deviation of disorder $\left(\sigma_{\mathrm{D}}\right)$ is related to the reorganization energy through the equation $\sigma_{\mathrm{D}}^{2}=2 \lambda_{\mathrm{A}} \mathrm{k}_{\mathrm{B}} \mathrm{T}$; it can be computed through a combination of time-dependent MD simulations and DFT calculations, as described previously. ${ }^{27}$ The results obtained from these calculations, see Table 3, are comparable to the relaxation energies obtained from the potential energy 
surfaces. We stress again that these results point to larger reorganization energies for the multiadduct PCBMs. Hence, care must be taken when designing larger, flexible adducts for fullerenes.

In amorphous films, there occurs a substantial amount of static disorder in addition to dynamic disorder. We have shown recently ${ }^{57}$ that the disorder derived from an ensemble average accounts for both static and dynamic components and can therefore be referred to as the total disorder. When these two components are statistically independent, as is the case here, and each exhibit a Gaussian distribution, the total disorder can be represented as a convolution of static and dynamic components, $\sigma_{\mathrm{T}}^{2}=\sigma_{\mathrm{D}}^{2}+\sigma_{\mathrm{S}}^{2}$. This formula was used to derive the results reported in Table 4.

Table 4: Overall disorder computed from the distribution of HOMO eigenvalues of the anionic fullerene derivatives with the point charges of the surrounding first-neighbor molecules included from a single frame of a MD trajectory. The $\sigma_{\mathrm{T}}$ values are accurate within $0.01 \mathrm{eV}, 0.01 \mathrm{eV}$, and $0.02 \mathrm{eV}$ for mono-adducts, bis-adducts, and tris-adducts, respectively.

\begin{tabular}{l|c|c|c|c|c|c}
\hline \multicolumn{6}{c}{ Anion Disorder in the Condensed Phase } \\
\hline & \multicolumn{3}{c}{ Indene_(e) } & \multicolumn{3}{c}{ PCBM } \\
\hline & $\sigma_{\mathbf{T}}$ & $\boldsymbol{\sigma}_{\mathbf{S}}$ & $\boldsymbol{\sigma}_{\mathrm{D}}$ & $\boldsymbol{\sigma}_{\mathbf{T}}$ & $\boldsymbol{\sigma}_{\mathbf{S}}$ & $\boldsymbol{\sigma}_{\mathrm{D}}$ \\
\hline mono & 0.10 & 0.07 & 0.07 & 0.13 & 0.10 & 0.08 \\
\hline bis1 & 0.11 & 0.08 & 0.07 & 0.14 & 0.11 & 0.08 \\
\hline bis2 & 0.16 & 0.14 & 0.07 & 0.15 & 0.10 & 0.11 \\
\hline tris & 0.12 & 0.10 & 0.07 & 0.12 & 0.08 & 0.09 \\
\hline
\end{tabular}


The total disorder obtained for the mono-adduct PCBM is 30\% larger than that of the monoadduct indene- $\mathrm{C}_{60}$. Taking into consideration the difference in relaxation energy or $\sigma_{\mathrm{D}}$ (since $\lambda$ is proportional to $\sigma^{2}$, differences in $\lambda$ translate into smaller differences in $\sigma$ ) between the monoadducts of indene- $\mathrm{C}_{60}$ and PCBM, we obtain static disorders of $0.07 \mathrm{eV}$ and $0.11 \mathrm{eV}$ for the indene and PCBM mono-adducts, respectively. The $>50 \%$ larger static disorder in PCBM would suggest a smaller electron mobility in PCBM amorphous thin films when compared to films of indene- $\mathrm{C}_{60}$. In contrast, indene- $\mathrm{C}_{60}$ amorphous films were found experimentally to have electron mobilities on the order of $0.04-0.07 \mathrm{~cm}^{2} \mathrm{~V}^{-1} \mathrm{~s}^{-1}$, which are in the same range as those reported for PCBM, $0.05-0.10 \mathrm{~cm}^{2} \mathrm{~V}^{-1} \mathrm{~s}^{-1} .^{58,59}$ An explanation for this observation is that the mono-adduct of indene- $\mathrm{C}_{60}$ has been shown to have poor film forming capability when compared to PCBM (when using halogenated solvents); ${ }^{23}$ this suggests that the actual disorder in such indene- $\mathrm{C}_{60}$ films could be larger than what is estimated in our work.

In the case of the bis-adducts of indene- $\mathrm{C}_{60}$, the largest standard deviation is computed for the static disorder of the bis 2 adduct, $0.14 \mathrm{eV}$. It is useful to recall that the bis 2 adduct has a smaller pseudo first-order transition (melting) temperature when compared to bis1, indicative of potentially easier routes to disrupt local packing; this is consistent with larger variations in the first-neighbor environments. Thus, the differences in the packing environments translate into higher total and static disorders for the bis 2 adduct of indene- $\mathrm{C}_{60}$ with respect to the bis 1 adduct. In the case of PCBM, there are no significant differences in the disorder parameters between the bis1 and bis2 adducts, which is consistent with the similar pseudo first-order transition temperatures, see Table 2.

Comparing the bis-adducts of indene- $\mathrm{C}_{60}$ and PCBM, the average total disorder of the bisadducts of indene- $\mathrm{C}_{60}$ is $0.01 \mathrm{eV}$ lower than the average of the bis-adducts of PCBM. Recent 
impedance spectroscopy measurements ${ }^{60}$ of disorder in an indene- $\mathrm{C}_{60}$ bis-adduct films within an hybrid-bilayer perovskite solar cell, yield a value of $0.188 \mathrm{eV}$, which is slightly higher than the maximum value of $0.16 \mathrm{eV}$ we have calculated for the bis 2 adduct. The measured higher degree of disorder compared to our results can be attributed, at least partly, to the presence of various interfaces within the devices and of isomeric mixtures of indene- $\mathrm{C}_{60}$ bis-adducts.

The results collected in Table 4 indicate that, among the PCBM compounds, tris-adducts have the lowest total and static disorders. In the case of indene- $\mathrm{C}_{60}$, the $\sigma_{\mathrm{T}}$ and $\sigma_{\mathrm{S}}$ values derived for the tris-adduct are larger than those for the mono-adduct but smaller than the averaged values estimated for the bis-adducts. We note, however, that the films of bis-adducts and tris-adducts usually represent mixtures of various isomers. Field-effect transistor measurements point to reduced electron mobilities in multi-adducts of $\mathrm{PCBM}$ and indene- $\mathrm{C}_{60}$ when compared to their mono-adduct counterparts. ${ }^{37,58,59}$ Kinetic Monte Carlo studies from Nelson and co-workers on a PCBM-adduct series attributed ${ }^{8,11}$ this trend to increased isomeric disorder with an increase in the number of adducts. Based only on the dependence of the electron affinity on the isomer chemical structure, isomeric disorder can be as large as $70 \mathrm{meV}$ in bis-adducts of indene- $\mathrm{C}_{60}$ and PCBM and larger than $100 \mathrm{meV}$ in tris-adducts. ${ }^{8,11,36}$ As mentioned above, our calculations also indicate that there could be significant differences in the static disorder among isomers. Therefore, further investigations are required to provide an analysis of the nature and extent of disorder for isomeric mixtures and how that disorder impacts the magnitude of the electron mobilities computed on the basis of the simulations results. 


\section{Conclusions}

A computational approach that combines molecular dynamics simulations and density functional theory was used to investigate how the nature and number of solubilizing adducts appended to $\mathrm{C}_{60}$ impact major solid-state parameters associated with charge-carrier transport in thin films. The methodology allows us to describe the topological connectivity within the bulk to pinpoint the differences between the types of disorder (dynamic and static disorders).

At the single-molecule level, our results for the substituted fullerenes indicate that:

i) The dynamic disorder / reorganization energy are smaller for the indene-based adducts, when compared to the fullerene derivatives based on butyric-acid-methyl-ester adducts.

ii) The larger butyric-acid-methyl-ester adducts slightly increase the reorganization energy, an effect in part due to the ability of the long chains to influence the electron localization on the fullerene cage. This influence is different for neutral and radical-anion moieties and varies with adduct position, leading to an asymmetry in the related relaxation energies. This result suggests that large adducts can be detrimental to the charge-carrier transport characteristics of fullerenes.

From the solid-state packing studies, the following conclusions can be drawn:

i) The smaller indene-based adducts provide denser packing and a larger number of nearest neighbor molecules compared to the PCBM-based fullerene derivatives.

ii) Smaller rigid adducts can provide directionality to the interactions, because of entropic considerations, which can influence the formation of ordered phases (partly 
ordered phases in the bis 1 adduct of indene- $\mathrm{C}_{60}$ ) that possess lower structural and energetic disorders.

iii) There is no clear correlation between the degree of disorder and the number of adducts, since disorder increases when going from mono- to bis-substituted molecules but decreases upon addition of the third adduct.

iv) The substitution pattern, as seen in particular in the case of bis-indene adducts, can have a strong effect on the static disorder.

v) Overall the polar, flexible butyric acid ethyl ester adducts lead to larger static and dynamic disorders when compared to the indene adducts.

vi) In the thin-film simulations, the numbers of isolated molecules are found to be higher in tris-adducts of indene- $\mathrm{C}_{60}$ and tris-PCBM. Such disconnected molecules can behave as energetic traps due to their low electronic connectivity and are detrimental to electron transport.

Overall, the main message from our work is that smaller adducts that lead to limited adductadduct interactions can fulfill their role in terms of increased solubility without increasing the extent of disorder and compromising the number of nearest neighbors and pathways for electron transport.

\section{Acknowledgements}

We acknowledge financial support of this work at the Georgia Institute of Technology by the Deanship of Scientific Research of King Abdulaziz University under an International 
Collaboration Grant (Award No. D-001-433), the Department of the Navy - Office of Naval Research under the MURI "Center for Advanced Organic Photovoltaics" (Award No. N0001414-1-0580 and N00014-16-1-2520), and King Abdullah University of Science and Technology (V.C.). The work at the King Abdullah University of Science and Technology has been supported by the KAUST competitive research funding and the Office of Naval Research Global (Award No. N62909-15-1-2003). C.R. thanks the University of Kentucky Vice President for Research for start-up funds. 


\section{References}

1. Mihailetchi, V. D.; van Duren, J. K. J.; Blom, P. W. M.; Hummelen, J. C.; Janssen, R. A. J.; Kroon, J. M.; Rispens, M. T.; Verhees, W. J. H.; Wienk, M. M., Electron Transport in a Methanofullerene. Adv. Funct. Mater. 2003, 13, 43-46.

2. Bendikov, M.; Wudl, F.; Perepichka, D. F., Tetrathiafulvalenes, Oligoacenenes, and Their Buckminsterfullerene Derivatives: The Brick and Mortar of Organic Electronics. Chem. Rev. 2004, 104, 4891-4946.

3. Anthopoulos, T. D.; Tanase, C.; Setayesh, S.; Meijer, E. J.; Hummelen, J. C.; Blom, P. W. M.; de Leeuw, D. M., Ambipolar Organic Field-Effect Transistors Based on a SolutionProcessed Methanofullerene. Adv. Mater. 2004, 16, 2174-2179.

4. Thompson, B. C.; Fréchet, J. M. J., Polymer-Fullerene Composite Solar Cells. Angew. Chem. Int. Ed. 2008, 47, 58-77.

5. Kippelen, B.; Bredas, J. L., Organic Photovoltaics. Energy Environ. Sci. 2009, 2, 251261.

6. He, Y.; Li, Y., Fullerene Derivative Acceptors for High Performance Polymer Solar Cells. Phys. Chem. Chem. Phys. 2011, 13, 1970-1983.

7. Nielsen, C. B.; Holliday, S.; Chen, H.-Y.; Cryer, S. J.; McCulloch, I., Non-Fullerene Electron Acceptors for Use in Organic Solar Cells. Acc. Chem. Res. 2015, 48, 2803-2812.

8. Frost, J. M.; Faist, M. A.; Nelson, J., Energetic Disorder in Higher Fullerene Adducts: A Quantum Chemical and Voltammetric Study. Adv. Mater. 2010, 22, 4881-4884.

9. Savoie, B. M.; Kohlstedt, K. L.; Jackson, N. E.; Chen, L. X.; Olvera de la Cruz, M.; Schatz, G. C.; Marks, T. J.; Ratner, M. A., Mesoscale Molecular Network Formation in Amorphous Organic Materials. Proc. Natl. Acad. Sci. USA 2014, 111, 10055-10060.

10. Jackson, N. E.; Savoie, B. M.; Chen, L. X.; Ratner, M. A., A Simple Index for Characterizing Charge Transport in Molecular Materials. J. Phys. Chem. Lett. 2015, 6, 10181021.

11. Steiner, F.; Foster, S.; Losquin, A.; Labram, J.; Anthopoulos, T. D.; Frost, J. M.; Nelson, J., Distinguishing the Influence of Structural and Energetic Disorder on Electron Transport in Fullerene Multi-Adducts. Mater. Horiz. 2015, 2, 113-119.

12. Dabirian, R.; Feng, X.; Ortolani, L.; Liscio, A.; Morandi, V.; Mullen, K.; Samori, P.; Palermo, V., Micron-Sized [6,6]-Phenyl C61 Butyric Acid Methyl Ester Crystals Grown by Dip Coating in Solvent Vapour Atmosphere: Interfaces for Organic Photovoltaics. Phys. Chem. Chem. Phys. 2010, 12, 4473-4480.

13. Ball, J. M.; Bouwer, R. K. M.; Kooistra, F. B.; Frost, J. M.; Qi, Y.; Domingo, E. B.; Smith, J.; de Leeuw, D. M.; Hummelen, J. C.; Nelson, J., et al., Soluble Fullerene Derivatives: The Effect of Electronic Structure on Transistor Performance and Air Stability. J. Appl. Phys. 2011, 110, 014506-014509.

14. Schafferhans, J.; Deibel, C.; Dyakonov, V., Electronic Trap States in Methanofullerenes. Adv. Energy Mat. 2011, 1, 655-660.

15. Liu, H.-W.; Chang, D.-Y.; Chiu, W.-Y.; Rwei, S.-P.; Wang, L., Fullerene Bisadduct as an Effective Phase-Separation Inhibitor in Preparing Poly(3-Hexylthiophene)-[6,6]-Phenyl-C61Butyric Acid Methyl Ester Blends with Highly Stable Morphology. J. Mater. Chem. 2012, 22, 15586-15591.

16. Larson, B. W.; Whitaker, J. B.; Wang, X.-B.; Popov, A. A.; Rumbles, G.; Kopidakis, N.; Strauss, S. H.; Boltalina, O. V., Electron Affinity of Phenyl-C61-Butyric Acid Methyl Ester (PCBM). J. Phys. Chem. C 2013, 117, 14958-14964. 
17. Kaiser, A.; Probst, M.; Stretz, H. A.; Hagelberg, F., Aggregates of PCBM Molecules: A Computational Study. Int. J. Mass spectrom. 2014, 365-366, 225-231.

18. Ide, J.; Fazzi, D.; Casalegno, M.; Meille, S. V.; Raos, G., Electron Transport in Crystalline PCBM-Like Fullerene Derivatives: A Comparative Computational Study. J. Mat. Chem. C 2014, 2, 7313-7325.

19. Zhang, J.; Li, C.-Z.; Williams, S. T.; Liu, S.; Zhao, T.; Jen, A. K. Y., Crystalline CoAssemblies of Functional Fullerenes in Methanol with Enhanced Charge Transport. J. Am. Chem. Soc. 2015.

20. Cheung, D. L.; Troisi, A., Theoretical Study of the Organic Photovoltaic Electron Acceptor PCBM: Morphology, Electronic Structure, and Charge Localization. J. Phys. Chem. C 2010, 114, 20479-20488.

21. Frigerio, F.; Casalegno, M.; Carbonera, C.; Nicolini, T.; Meille, S. V.; Raos, G., Molecular Dynamics Simulations of the Solvent- and Thermal History-Dependent Structure of the PCBM Fullerene Derivative. J. Mater. Chem. 2012, 22, 5434-5443.

22. Coropceanu, V.; Cornil, J.; da Silva, D. A.; Olivier, Y.; Silbey, R.; Bredas, J. L., Charge Transport in Organic Semiconductors. Chem. Rev. 2007, 107, 926-952.

23. Sabirov, D. S.; Terentyev, A. O.; Bulgakov, R. G., Counting the Isomers and Estimation of Anisotropy of Polarizability of the Selected C60 and C70 Bisadducts Promising for Organic Solar Cells. J. Phys. Chem. A 2015, 119, 10697-10705.

24. Jorgensen, W. L.; Maxwell, D. S.; Tirado-Rives, J., Development and Testing of the OPLS All-Atom Force Field on Conformational Energetics and Properties of Organic Liquids. $J$. Am. Chem. Soc. 1996, 118, 11225-11236.

25. Wang, C. I.; Hua, C. C., Solubility of C60 and PCBM in Organic Solvents. J. Phys. Chem. B 2015, 119, 14496-14504.

26. Tummala, N. R.; Mehraeen, S.; Fu, Y. T.; Risko, C.; Bredas, J. L., Materials-Scale Implications of Solvent and Temperature on [6,6]-Phenyl-C61-Butyric Acid Methyl Ester (PCBM): A Theoretical Perspective. Adv. Funct. Mater. 2013, 23, 5800-5813.

27. Tummala, N. R.; Bruner, C.; Risko, C.; Bredas, J. L.; Dauskardt, R. H., Molecular-Scale Understanding of Cohesion and Fracture in P3HT:Fullerene Blends. ACS Appl. Mater. Inter. 2015, 7, 9957-9964.

28. Williams, M.; Tummala, N. R.; Aziz, S. G.; Risko, C.; Brédas, J.-L., Influence of Molecular Shape on Solid-State Packing in Disordered PC61BM and PC71BM Fullerenes. $J$. Phys. Chem. Lett. 2014, 5, 3427-3433.

29. Watt, S. W.; Chisholm, J. A.; Jones, W.; Motherwell, S., A Molecular Dynamics Simulation of the Melting Points and Glass Transition Temperatures of Myo- and Neo-Inositol. J. Chem. Phys. 2004, 121, 9565-9573.

30. Wang, Y.; Teitel, S.; Dellago, C., Melting of Icosahedral Gold Nanoclusters from Molecular Dynamics Simulations. J. Chem. Phys. 2005, 122, 214722.

31. Steinhardt, P. J.; Nelson, D. R.; Ronchetti, M., Bond-Orientational Order in Liquids and Glasses. Physical Review B 1983, 28, 784-805.

32. Baer, R.; Livshits, E.; Salzner, U., Tuned Range-Separated Hybrids in Density Functional Theory. Annu. Rev. Phys. Chem. 2010, 61, 85-109.

33. Körzdörfer, T.; Brédas, J.-L., Organic Electronic Materials: Recent Advances in the DFT Description of the Ground and Excited States Using Tuned Range-Separated Hybrid Functionals. Acc. Chem. Res. 2014, 47, 3284-3291. 
34. Coropceanu, V.; Sánchez-Carrera, R. S.; Paramonov, P.; Day, G. M.; Brédas, J.-L., Interaction of Charge Carriers with Lattice Vibrations in Organic Molecular Semiconductors: Naphthalene as a Case Study. J. Phys. Chem. C 2009, 113, 4679-4686.

35. Lenes, M.; Shelton, S. W.; Sieval, A. B.; Kronholm, D. F.; Hummelen, J. C.; Blom, P. W. M., Electron Trapping in Higher Adduct Fullerene-Based Solar Cells. Adv. Funct. Mater. 2009, 19, 3002-3007.

36. Nardes, A. M.; Ferguson, A. J.; Whitaker, J. B.; Larson, B. W.; Larsen, R. E.; Maturová, K.; Graf, P. A.; Boltalina, O. V.; Strauss, S. H.; Kopidakis, N., Beyond PCBM: Understanding the Photovoltaic Performance of Blends of Indene-C60 Multiadducts with Poly(3Hexylthiophene). Adv. Funct. Mater. 2012, 22, 4115-4127.

37. Kang, H.; Cho, C.-H.; Cho, H.-H.; Kang, T. E.; Kim, H. J.; Kim, K.-H.; Yoon, S. C.; Kim, B. J., Controlling Number of Indene Solubilizing Groups in Multiadduct Fullerenes for Tuning Optoelectronic Properties and Open-Circuit Voltage in Organic Solar Cells. ACS Appl. Mater. Inter. 2012, 4, 110-116.

38. Hildebrand, J. H.; Scott, R. L., The Entropy of Solution of Nonelectrolytes. J. Chem. Phys. 1952, 20, 1520-1521.

39. Hansen, C. M., The Three Dimensional Solubility Parameter-Key to Paint Component Affnitiies: I. Solvents, Plasticizers, Polymers and Resins. Journal of Paint Technology 1967, 39, 104-.

40. The Hildebrand parameters are evaluated from the density and total interaction energy from the amorphous bulk simulations and the isolated moleucle simulations within the same volume as the amorphous bulk. The Hansen parameters are computed based on the short and long-range dispeerison and electrostic contributions to the total interaction energy for the amorphous bulk and isolaed molecule simulations, respectively. Theinteraction energy parameters are extracted from the GROMACS software output files.

41. Hansen, C. M.; Smith, A. L., Using Hansen Solubility Parameters to Correlate Solubility of C60 Fullerene in Organic Solvents and in Polymers. Carbon 2004, 42, 1591-1597.

42. Zhao, G.; He, Y.; Li, Y., 6.5\% Efficiency of Polymer Solar Cells Based on Poly(3Hexylthiophene) and Indene-C60 Bisadduct by Device Optimization. Adv. Mater. 2010, 22, 4355-4358.

43. Machui, F.; Abbott, S.; Waller, D.; Koppe, M.; Brabec, C. J., Determination of Solubility Parameters for Organic Semiconductor Formulations. Macromol. Chem. Phys. 2011, 212, 21592165.

44. Moulé, A. J.; Meerholz, K., Controlling Morphology in Polymer-Fullerene Mixtures. Adv. Mater. 2008, 20, 240-245.

45. Zuo, C.; He, D.; Xiao, Z.; Ding, L., Replacing Indenes on Fullerene with CH2 Groups Benefits Photovoltaic Performance. Sci. China Chem. 2014, 58, 370-372.

46. Ryan, J. W.; Matsuo, Y., Increased Efficiency in Small Molecule Organic Solar Cells through the Use of a 56-П Electron Acceptor - Methano Indene Fullerene. Sci. Rep. 2015, 5, 8319.

47. Matsuo, Y.; Kawai, J.; Inada, H.; Nakagawa, T.; Ota, H.; Otsubo, S.; Nakamura, E., Addition of Dihydromethano Group to Fullerenes to Improve the Performance of Bulk Heterojunction Organic Solar Cells. Adv. Mater. 2013, 25, 6266-6269.

48. Zhao, J.; Swinnen, A.; Van Assche, G.; Manca, J.; Vanderzande, D.; Mele, B. V., Phase Diagram of P3HT/PCBM Blends and Its Implication for the Stability of Morphology. J. Phys. Chem. B 2009, 113, 1587-1591. 
49. Larson, B. W.; Whitaker, J. B.; Popov, A. A.; Kopidakis, N.; Rumbles, G.; Boltalina, O. V.; Strauss, S. H., Thermal [6,6] $\rightarrow$ [6,6] Isomerization and Decomposition of PCBM (PhenylC61-Butyric Acid Methyl Ester). Chem. Mater. 2014, 26, 2361-2367.

50. De Michele, C.; Schilling, R.; Sciortino, F., Dynamics of Uniaxial Hard Ellipsoids. Phys. Rev. Lett. 2007, 98, 265702.

51. Foffi, G.; Götze, W.; Sciortino, F.; Tartaglia, P.; Voigtmann, T., Mixing Effects for the Structural Relaxation in Binary Hard-Sphere Liquids. Phys. Rev. Lett. 2003, 91, 085701.

52. Mickel, W.; Kapfer, S. C.; Schröder-Turk, G. E.; Mecke, K., Shortcomings of the Bond Orientational Order Parameters for the Analysis of Disordered Particulate Matter. J. Chem. Phys. 2013, 138, 044501.

53. Zhao, F.; Meng, X.; Feng, Y.; Jin, Z.; Zhou, Q.; Li, H.; Jiang, L.; Wang, J.; Li, Y.; Wang, C., Single Crystalline Indene-C60 Bisadduct: Isolation and Application in Polymer Solar Cells. J. Mat. Chem. A 2015, 3, 14991-14995.

54. Guilbert, A. A. Y.; Reynolds, L. X.; Bruno, A.; MacLachlan, A.; King, S. P.; Faist, M. A.; Pires, E.; Macdonald, J. E.; Stingelin, N.; Haque, S. A., et al., Effect of Multiple Adduct Fullerenes on Microstructure and Phase Behavior of P3HT:Fullerene Blend Films for Organic Solar Cells. ACS Nano 2012, 6, 3868-3875.

55. Orgiu, E.; Squillaci, M. A.; Rekab, W.; Borjesson, K.; Liscio, F.; Zhang, L.; Samori, P., The Dramatic Effect of the Annealing Temperature and Dielectric Functionalization on the Electron Mobility of Indene-C60 Bis-Adduct Thin Films. Chem. Commun. 2015, 51, 5414-5417.

56. Sokolov, A. N.; Atahan-Evrenk, S.; Mondal, R.; Akkerman, H. B.; Sánchez-Carrera, R. S.; Granados-Focil, S.; Schrier, J.; Mannsfeld, S. C. B.; Zoombelt, A. P.; Bao, Z., et al., From Computational Discovery to Experimental Characterization of a High Hole Mobility Organic Crystal. Nat. Commun. 2011, 2, 437.

57. Tummala, N. R.; Zheng, Z.; Aziz, S. G.; Coropceanu, V.; Brédas, J.-L., Static and Dynamic Energetic Disorders in the C60, PC61BM, C70, and PC71BM Fullerenes. J. Phys. Chem. Lett. 2015, 3657-3662.

58. Li, C.-Z.; Chueh, C.-C.; Yip, H.-L.; Zou, J.; Chen, W.-C.; Jen, A. K. Y., Evaluation of Structure-Property Relationships of Solution-Processible Fullerene Acceptors and Their NChannel Field-Effect Transistor Performance. J. Mater. Chem. 2012, 22, 14976-14981.

59. Yu, H.; Cho, H.-H.; Cho, C.-H.; Kim, K.-H.; Kim, D. Y.; Kim, B. J.; Oh, J. H., Polarity and Air-Stability Transitions in Field-Effect Transistors Based on Fullerenes with Different Solubilizing Groups. ACS Appl. Mater. Inter. 2013, 5, 4865-4871.

60. Shao, Y.; Yuan, Y.; Huang, J., Correlation of Energy Disorder and Open-Circuit Voltage in Hybrid Perovskite Solar Cells. Nat. Energy. 2016, 1, 15001. 
Table of Contents Graphic:

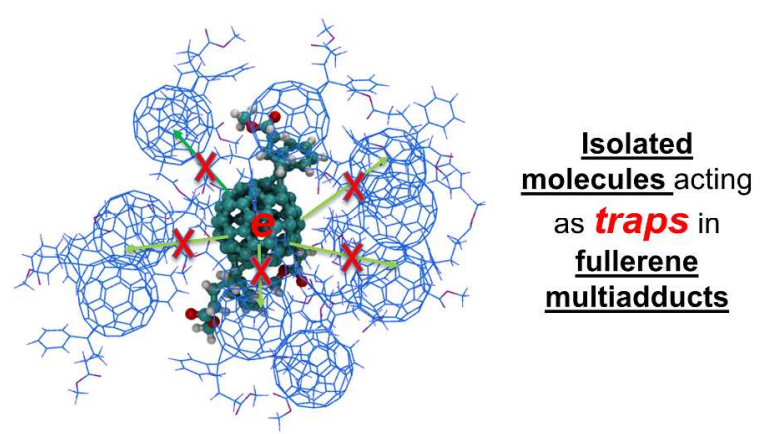

